\title{
Rekreasyonel Faaliyetlerde Etkinlik Doyum Ölçeğinin Türkçe Uyarlamas1
}

\author{
İsmail AYDIN ${ }^{1}$
}

Öz

Bu çalısmada, Oliver'ın (1980) geliştirdiği Funk, Jordan, Ridinger ve Kaplanidou'nun (2011) serbest zaman literatürüne uyarladığı Etkinlik Doyum Ölçeği'nin (EDÖ) hem Türkçe geçerlik-güvenirliğinin test edilmesi hem de psikometrik özelliklerinin incelenmesi amaçlanmıştır. Araştırmanın çalışma gurubunu sağlık ve zindelik kulüplerinden rekreasyonel amaçlı fiziksel etkinlik hizmeti alan 391 kişi oluşturmaktadır. Katılımcılara tamamına "Etkinlik Doyum Ölçeği”, "Oxford Mutluluk Ölçeği Kısa Formu (OMÖ-K)”, “Öznel Mutluluk Ölçeği (ÖMÖ)”, "Yaşam Doyum Ölçeği (YDÖ)" ve "Rekreasyonda Akış Deneyim Ölçeği (RADÖ)” uygulanmıştır. Dil geçerliliği yapılan EDÖ’nün yap1 geçerliği için "Doğrulayıc1 Faktör Analizinden (DFA)" yararlanılmış, Ölçüt Bağıntılı Geçerliği için kullanılan diğer ölçeklerle olan ilişkisi hesaplanmıştır. EDÖ’nün güvenirlik düzeyi için ise iç güvenirlik katsayısı kullanılmıştır. DFA sonucunda belirlenen değerler, ölçeğin tek boyutlu yapısının Türk kültüründeki oluşan katılımcılarda da korunduğunu göstermektedir. Ölçüt bağıntılı geçerlik için yapılan analizi doyumu değerlendiren diğer ölçüm araçlarıyla EDÖ’nün istatiksel olarak anlamlı bir ilişkisinin olduğunu ortaya koymaktadır. Ayrıca EDÖ’nün iç güvenirlik değeri 0.91 olarak bulunmuştur. Araştırma kapsamında elde edilen bulguların EDÖ Türkçe formun tek faktörlü bir yapıda kabul edilebileceğini, bu formun rekreasyonel etkinliklere katılan katılımcıların etkinlik doyum düzeylerini değerlendirmede güvenilir ve geçerli bir ölçüm aracı olarak kabul edilebileceğini göstermektedir.

Anabtar Kelimeler: Etkinlik Doyumu, Güvenirlilik, Geçerlilik, Rekreasyon, Serbest Zaman

\section{Turkish Adaption of Event Satisfaction Scale in Recreational Activities}

\section{Abstract}

The aim of this study was to test Turkish reliability and validity of the "Event Satisfaction Scale" (ESS) developed by Oliver (1980), adapted to the leisure literature by Funk et al. (2011) and to examine its psychometric properties in the study. The research's study group consisted of 391 individuals who receive recreational physical activity services from health and wellness clubs. "Event Satisfaction Scale" (ESS), "Oxford Happiness Questionnaire Short Form (OHQ-SF)", "Subjective Happiness Scale (SHS)", "Life Satisfaction Scale (LSS)" and "Recreational Flow Experience Scale (RFES)" were applied to all participants. "Confirmatory Factor Analysis (CFA)" was used for ESS's construct validity, for criterion related validity, the correlations of ESS with other measuring methods used within the study were checked after ensuring the linguistic equivalence. The reliability of ESS was examined with composite reliability. The CFA result revealed that the single-factor structure of the scale was retained in the sample comprising Turkish people. The analysis performed for criterion related validity reveals that there was a statistically significant relationship between the other measurement tools that evaluate satisfaction and the ESS. In addition, the internal reliability value of the scale was found to be 0.91 . The findings obtained from the study demonstrated that the Turkish version of the ESS might be accepted as a single factor structure, and that this form could be used as a valid and reliable measurement tool in evaluating the activity satisfaction levels of participants participating in recreational activities.

Key Words: Event Satisfaction, Leisure, Validity, Reliability, Recreation

\section{Atıf İçin / Please Cite As:}

Aydın, İ. (2022). Rekreasyonel faaliyetlerde etkinlik doyum ölçeğinin Türkçe uyarlaması. Manas Sosyal Araștırmalar Dergisi, 11(1), 420-427.

Geliş Tarihi / Received Date: 16.04.2021

Kabul Tarihi / Accepted Date: 19.07.2021

\footnotetext{
${ }^{1}$ Dr. Öğr. Üyesi - Bartın Üniversitesi Spor Bilimleri Fakültesi, ismail.aydin2013@gmail.com

iD ORCID: 0000-0002-4373-7200
} 


\section{Giriş}

Serbest zaman etkinliklerine katıllım sonucunda oluşan memnuniyet düzeyini bilmek, bu tür etkinliklerin sosyal psikolojik açıdan incelenmesinde araştırmacılara oldukça katkı sağlamaktadır. Bazı araştırmacilar (Ateca-Amestoy, 2011, s. 10; Newman, Tay ve Diener, 2014, s. 558; Stiglitz, Sen ve Fitoussi, 2009, s. 14; Van Praag ve Ferrer-i-Carbonell, 2004, s. 69) bu tür etkinliklerden doğan memnuniyetin kişilerin etkinliklere yönelik tutumlarını, genel refah ve yaşam doyum düzeyleri gibi birçok konudaki ilişkilerin de keşfedilmesinde katkı sağlayacağını düşünmektedir. Bu sebeple serbest zaman etkinliklerinde geçirilen zaman ve gerçekleştirilen faaliyetlerden kişilerin ne ölçüde memnun oldukları ağırlıklı olarak kesitsel tasarımlı araştırmalar, daha az ise boylamsal araştırma tasarımlarıyla değerlendirmeye çalışılmaktadır. Tabi ki, kullanılan araştırma tasarımlarına bakılmaksızın serbest zaman etkinliklerinden doğan memnuniyetin insanlar arasında değişkenlik göstermesi bu konuyu ilginç bir fenomen haline getirdiği söylenebilir.

Her ne kadar serbest zaman literatüründe bu tür doyum düzeylerinin daha çok serbest zaman doyumu başlı̆ı altında incelendiği görülse de farklı başlıklarla da bu konunun değerlendirilmeye çalışıldığı bilinmektedir. Örneğin Funk vd. (2011, s. 252) kitle kattlımlı spor etkinliklerine katılımdan elde edilen doyumun bireysel bir şekilde etkinlik yapmaktan oluşan doyumdan daha farklı olabileceğini, dolayısıyla bu durumunda farklı bir ölçüm aracıyla değerlendirilmesi gerektiğini savunmuştur. Bu sebeple Funk vd. araştırmasında Oliver'ın (1980, s. 257) çalışmasından yararlanılarak oluşturduğu etkinlik doyum ölçeği kullanmıştır. Benzer şekilde, rekreasyonel faaliyetlerin insanlara özgür bir seçim şansı sunması, bu tür etkinliklerle kendilerini ifade etme firsatı sağlaması serbest zaman literatüründe etkinliklerinden doğan hazzı değerlendirmede Csikszentmihalyi, Larson ve Prescott (1977) tarafindan ilk olarak sosyal psikoloji alanına kullanılan akış deneyimi teriminin de yer almasına neden olmuştur. Akış deneyimi "kiş̧ilerin amaçlar doğrultusunda dikekatlerinin büyük oranm yaşadiğ deneyime yöneltmesi ve bunun sonucunda da bu faaliyetten mutluluk. duyması" şeklinde tanımlanmaktadır (Csikszentmihalyi, 1990, s. 5). Serbest zaman etkinlikleri söz konusu olduğunda, oluşan tecrübenin akış deneyimi düzeyini belirlemek için literatürde çeşitli ölçüm araçlarının geliştirildiği görülmektedir. Örneğin yurtiçi literatürde kişilerin rekreasyonel etkinliklere katılım sonucu oluşan psikolojik doyum düzeylerini belirlemek için Ayhan vd. (2020) tarafindan rekreasyonel deneyim ölçeğini test etmiştir. Bunun yanı sıra, bu tür etkinliklerin fizyolojik, estetik, rahatlama, sosyal ve psikolojik yönden bireylere sağladığı memnuniyet düzeylerini anlamada serbest zaman tatmin ölçeklerinin kullanıldığ1 da görülmektedir (ör. Beard ve Raghed, 1980, s. 20; Karlı, Polat, Yılmaz ve Koçak, 2008, s. 80).

Etkinliklere katılım sonucu oluşan memnuniyetin insanların yaşamlarını değerlendirmelerine doğrudan katkıda sağladığı düşünülmektedir. Örneğin Theodorakis, Kiki Kaplonidou ve Karabaxoglou (2015, s. 97) tarafindan rekreasyonel koşu faaliyetlerine katılan kişiler üzerine yürütülen araştırmada, bu tür etkinliklerden duyulan hazzın katılımcıların deneyimsel mutluluğu üzerinde de olumlu bir etki yarattı̆̆, böylece genel yaşam doyum düzeylerini ciddi bir şekilde artırabileceği rapor edilmiştir. Neticede serbest zaman etkinliğine katılım deneyiminin olumlu bir şekilde vuku bulması insanların bu tür faaliyetlere git gide daha çok duygusal ve sembolik anlam yüklemesine de neden olacaktır (Filo, Funk ve O’brien, 2009, s. 89). Dolayısıyla etkinlik için atfedilen değer arttıkça katılımın ve oluşan hazzın da bir o kadar artacağı bir gerçektir (Addis ve Holbrook, 2001, s. 61). Bu durumun etkinliklerden duyulan hazzin/memnuniyetin temelini oluştururken yaşamdan duyulan genel memnuniyeti de artırabileceği söylenebilir (Oliver, 1997, s. 122).

Sonuç olarak, her ne kadar rekreasyonel faaliyetlere katılımın bireylerde oluşturduğu memnuniyeti anlamada farklı kavram ve ölçüm araçları kullanılsa da, bu ölçüm araçlarının temel de kişilerin konuya ilişkin farklı düzeydeki özelliklerini ölçtügü görülmektedir. Araştırmada, geçerlilik ve güvenirliliği test edilen Etkinlik Doyum Ölçeği'nin (EDÖ) temelde grup ya da kitlesel katılımlı serbest zaman faaliyetlerini merkeze aldığı, Türkiye'de ise bu faaliyetlerden doğan memnuniyeti ölçeğe yönelik çeşitli veri tabanlarında (ör. ULAKBİM SBVT, Milli kütüphane, Dergi Park, Yüksek Öğretim Kurumu (YÖK), Ulusal Tez Merkezi ve YÖK Akademik) hiçbir çalışmanın yapılmadığı belirlenmiştir. Dolayısıyla, bu durum araştırmacıları literatürde konuya ilişkin yapılacak geçerli ve güvenir bir ölçüm aracının Türkçe diline kazandırılmasına sevk etmektedir. Bu sebeple, araştırmanın amacı Oliver’ın (1980) geliştirdiği Funk vd. (2011) serbest zaman literatürüne uyarladığı "Etkinlik Doyum Ölçeği’nin” (EDÖ) Türkçe geçerlilikgüvenirliliğini test etmektedir. Ayrıca yukarıda bahsedilen hem genel yaşam doyum düzeyini belirleyen hem de rekreasyon alanında katılım memnuniyetini değerlendirdiği düşünülen diğer ölçüm araçları ile EDÖ’nün 
ilişkisini incelemenin EDÖ’nün ölçüt bağıntılı geçerliliğini anlamada araştırmacılara katkı sağlayacağı düşünülmektedir.

\section{Yöntem}

\section{Kat1lımc1lar}

Araştırmanın çalışma gurubunu Ankara'da çeşitli sağlık ve zindelik kulüplerinden rekreasyonel amaçlı fiziksel etkinlik hizmeti alan 391( Ort $\left._{\text {yas }}=34.89\right)$ kişi oluşturmaktadır. Katılımc1 grubunu belirleme sürecinde amaçlı örneklem yöntemlerinden ölçüt örnekleme yöntemi kullanılmıştır. Katılımcılar, düzenli ya da düzensiz bir biçimde bir yll ve daha fazla süredir fitnes etkinliğinde grup derslerine (ör. spinning, yoğa vb.) katıllyor olma, ölçütü dikkate alınarak belirlenmiştir. Araştırmaya katılan bireylerin \%56.8’i erkek, \%64.2'si bekâr, \%65.0'i orta düzeyde gelire sahip, \%63.9'u üniversite mezunu, \%72.1'inin düzenli biçimde, haftalık ortalama 2.59 gün ve 2.69 saat bu programlara katıldığı belirlenmiştir.

\section{Veri Toplama Araçları}

Etkinlik Doyum Ölçeğini (EDÖ) Oliver (1980) geliştirilmiş, Funk vd. (2011) ise uyarlamıştır. Tek alt boyut ve toplam 3 maddeden oluşan ölçek 7'li Likert tipindeki ifadelerin yer aldığ1 görülmektedir. Rekreasyonel etkinliklere katılan bireylerin etkinliklerden duydukları doyuma yönelik ifadelerin yer aldığ1 orijinal çalışmada EDÖ’nün güvenirlik katsayısı 0.78 olarak rapor edilmiştir. Bu araştırmada ise EDÖ’nün iç güvenirlik katsayısı 0.91 olarak hesaplanmıştır.

Oxford Mutluluk Ölçeği Kısa Formunu (OMÖ-K) Hills ve Argyle (2002) geliştirmiştir. Türkçe uyarlaması Doğan ve Akıncı Çötok (2010) tarafından yapılan 5'li Likert tipindeki OMÖ-K tek alt boyut, 7 ifadeden oluşmaktadır. İnsanların genel mutluluk düzeylerini değerlendiren ölçeğin iç güvenirlik katsayısının 0.74 olduğu belirlenmiştir. Ayrıca kısa formun yap1 geçerliğinin test aşamasında OMÖ-K ile birlikte Zung Depresyon Ölçeği (ZDÖ), Yaşam Doyumu Ölçeği (YDÖ) ve Yaşam Yönelimi Testi (YYT) de katılımcilara uygulanmıştır.

Öznel Mutluluk Ölçeğini (ÖMÖ), Lyubomirsky ve Lepper (1999) geliştirmiş, Türkçe adaptasyonunu Doğan ve Totan (2013) gerçekleştirmiştir. 7’li likertte cevaplanan ve kişilerin global öznel mutluluğu ölçen ÖMÖ tek boyut, 4 madden oluşmaktadır. Ölçeğin Türkçe faktör yapısını belirlemek için yapılan test sonucu elde edilen iç güvenirlik katsayısının farlı çalışma gruplarında 0.65-0.70 arasında değiştiği görülmüştür. Ayrıca Doğan ve Totan çalışmasında ÖMÖ ile OMÖ (Oxford Mutluluk Ölçeği) arasındaki ilişkiyi de $(\mathrm{r}=0.71, \mathrm{p}<0.05)$ test etmiştir.

Yaşam Doyum Ölçeğini (YDÖ), Diener, Emmons, Larsen ve Griffin (1985) geliştirmiş, Türkçe uyarlaması Yetim (1991) yapmışır. Katılımcıların yaşam doyum düzeylerini tespit etmeye yönelik ifadelerin yer aldığ 5 madde ve tek boyutlu YDÖ katılımcilar tarafindan 7'li Likert tipinde cevaplanabilmektedir. Orijinal ölçek çalısmasında Diener vd. ölçeğin iç güvenirlik katsayısını 0.87 olarak belirlerken, Yetim (1991) Türkçe dilinde ölçeğin iç güvenirliğini 0.76 olduğunu bildirmiştir. Bu araştırmada ise YDÖ'nün iç güvenirlik katsayısı 0.89 olarak hesaplanmışır.

Rekreasyonel Akııs Deneyim Ölçeği (RADÖ), kişilerin rekreasyonel etkinliklere katıllım sonucu oluşan psikolojik doyum düzeylerini belirlemek için yapı geçerliliği Ayhan ve Eskiler (2020) tarafindan yapılmıştır. 9 madde tek alt boyuttan oluşan RADÖ, 7’li Likert tipinde cevaplanmaktadır. Ayrıca iç güvenirlik katsayısı 0.93 olarak hesaplanan orijinal ölçek çalışmasında RADÖ ile SZİ̈ (Serbest Zaman İlgilenim Ölçeği) arasındaki ilişki de test edilmiştir. Buna göre, RADÖ ile SZIÖO arasındaki ilişki düşük ve orta düzey de olduğu bulunmuştur.

\section{İşlemler ve Analiz Süreci}

EDÖ'nün Türkçe uyarlama çalışması dil eşdeğerliliği ile başlamıştır. İlk olarak, EDÖ'de İngilizce formunda bulunan ifadelerin İngilizce dil alanında eğitimini almış üç akademisyen tarafindan çeviri geriçeviri yöntemiyle Türkçeye formu oluşturulmuştur. Daha sonra oluşturulan bu üç farklı çeviri formu ölçek uyarlama çalışmasında eğitimli, İngilizcesi iyi ya da daha yukarı düzeyde üç araştırmacı tarafından ayrı ayrı değerlendirilmiştir. Bunun sonucunda oluşturulan Türkçe form İngilizce dil bilgisi yüksek başka akademisyen tarafından tekrar İngilizceye çevrilmiş, İngilizce orijinal form ile Türkçe form arasındaki uyumu belirlenmiştir. Son olarak ölçek ifadelerinin anlaşılırlığ Türkçe formun pilot uygulaması yapılarak gözden geçirilmiş ve araştırmacılar tarafindan yurtiçi serbest zaman literatürde kullanılabilecek EDÖ Türkçe formunun son şekli verilmiştir. Ölçekte yer alan 3 madde sırasıyla şu şekildedir. (Madde 1) "Bu 
etkinliğe katılma kararmdan dolay memnunum”, (Madde 2) “Bu etkinliğe katıldiğım için mutluyum”, (Madde 3) "Bu etkinliğe katılma karar alarak doğru bir şey yaptım”. Ölçeğin dilsel eşdeğerliliği sağlandıktan sonra uygulamasına geçilmiştir.

Araştırmacı eşliğinde katılımcılardan toplanan veriler SPSS-23 ve AMOS-18 istatistiksel paket programlarında değerlendirilmiştir. Elde edilen verilerin parametrik test için ön şartı sağlayıp sağlamadığına tek değişkenli normallik dağılım test sonucuyla incelenmiş ve normal dağılım göstermesi sebebiyle parametrik tahmin yöntemi olan Maksimum olabilirlik çıkarımı (Maxsimum Likelihood: ML) araştırmada tercih edilmiştir. İlk olarak Türkçe çevirisi yapılan ölçeğin model uyumunu test etmek ve faktör yapısının doğrulamak amacıyla Doğrulayıcı Faktör Analizi (DFA) uygulanmıştır. Bunun yanı sıra ölçüm aracının Türkçe formunun iç güvenirliği için ölçüm aracının alt boyut düzeyinde Cronbach Alfa katsayıları belirlenmiştir; ayrıca, ölçüm araçlarının yapı güvenirliği için Composite Reliability (CR), yakınsama geçerliği ve ayırt edici geçerliliği için de Average Variance Extracted (AVE) araştırmada hesaplanmıştır (Tablo 1).

\section{Bulgular}

\section{Betimleyici İstatistik}

Araştırmada kullanılan ölçeklerin ortalama puanlarının sırasıyla EDÖ için 5.28, OMÖ-K için 3.42, ÖMÖ için 5.29, YDÖ için 5.36 ve RADÖ için 5.18 olduğu, Cronbach's Alpha iç güvenirlik katsayılarının 0.91-0.62 arasında değiştiği belirlenmiştir; ayrıca, yakınsama geçerlik kapsamında değerlendirilen açıklanan Ortalama Varyans değerinin (AVE) EDÖ için 0.79 olarak, Yap1 Güvenirliğinin (CR) ise 0.92 olarak hesaplandığ1 gözlemlenmiştir (Tablo 1). EDÖ boyutu için hesaplanan "yap1 güvenirliğinin” $(<0.70)$ olması analiz sonuçlarının güvenirliğinin kanıtı olarak kabul edilirken, yakınsama geçerliği için hesaplanan AVE’nin $(<0,50)$ değerinden büyük olması ise "yakınsama geçerliğinin kanıtı" olarak gösterilmektedir (Fornel ve Larcker, 1981; Peterson, 2000).

Tablo 1. Ölçeklerin Puan Dağ̊lımı (N=391)

\begin{tabular}{lccc}
\hline & Ort. (Ss.) & Bas. & Çarp. \\
\hline Etkinlik Doyum Ölçeği $(A V E=0.79, C R=0.92, a=0.91)$ & $5.28(0.91)$ & -0.46 & -0.39 \\
Oxford Mutluluk Ölçeği Kısa Formu $(a=0.62)$ & $3.42(0.62)$ & -0.25 & 0.31 \\
Öznel Mutluluk Ölçeği $(a=0.86)$ & $5.29(0.91)$ & -0.89 & 0.66 \\
Yaşam Doyum Ölçeği $(a=0.89)$ & $5.36(0.94)$ & -0.93 & 0.74 \\
Rekreasyonel Akış Deneyim Ölçeği $(a=0.66)$ & $5.18(0.58)$ & -0.56 & 0.29 \\
\hline
\end{tabular}

EDÖ’nün cinsiyet değişkeni acısından ele alındığında kadınların puanları 5.17 (Ss. = 1.04), erkeklerin ise 5.37 (Ss. 1.05) olarak tespit edilmiştir. Elde edilen puanların cinsiyete göre istatistiksel olarak anlamlı düzeyde farklılık göstermediği ( $\mathrm{t}=-1.82, \mathrm{p}=0.06)$ bağımsız örneklemler t-testi ile belirlenmiştir (Tablo 2).

Tablo 2. Etkinlike Doyum Ölçeği Toplam Puan Dağglimlarnmn Cinsiyete Göre İncelenmesi

\begin{tabular}{lcccc}
\hline & Toplam Katılımcı & Kadın & Erkek & t-değeri \\
\hline Etkinlik Doyum Ölçeği & Ort. (Ss.) & Ort. (Ss.) & Ort. (Ss.) & $5.37(1.05)$ \\
\hline
\end{tabular}

\section{Yapı Geçerliği}

DFA sonuçları incelendiğinde, EDÖ'de yer alan maddelerin faktör yükünün 0.93-0.81 arasında değiştiği görülmektedir (Tablo 3). DFA analizi sürecinde önerilen araştırma modelinin " $\chi 2 / \mathrm{sd}=1.68$ ”, "RMSEA = 0.04", "SRMR= 0.00”, “NFI= 0.99”, "CFI= 0.99”; "RMR=0.02” uyum değerlerine göre iyi uyum gösterdiği tespit edilmiştir (Tablo 4). EDÖ’nün faktör yapısı Şekil 1'de sunulmuştur.

Tablo 3. Doğrulayıcı Faktör Analiz Sonuclar

\begin{tabular}{lccc}
\hline \multicolumn{1}{c}{ Ölçek Maddeleri } & Standartlaştırılmiş Faktör Yükler & t-dĕg. & $\boldsymbol{t}^{2}$ \\
\hline Madde 1 & 0.93 & $32.0^{*}$ & 0.86 \\
Madde 2 & 0.93 & $31.9^{*}$ & 0.86 \\
Madde 3 & 0.81 & $24.0^{*}$ & 0.65 \\
\hline " $\leq 0.05$ & &
\end{tabular}


Tablo 4. Doğrulaync Faktör Analiz, Sonucunun Uyum Indeksleri

\begin{tabular}{lcc}
\hline \multicolumn{1}{c}{ Uyum Değerleri } & \multicolumn{1}{c}{ Uyum Ölçütleri } & Elde Edilen Değerler \\
\hline$\chi 2 / s d$ & $\leq 3$ iyi uyum, $\leq 4-5$ Kabul Edilebilir Uyum & 1.68 \\
RMSEA & $\leq 0.05$ iyi uyum, 0.06-0.08 Kabul Edilebilir Uyum & 0.04 \\
SRMR & $\leq 0.05$ iyi uyum, 0.06-0.08 Kabul Edilebilir Uyum & 0.00 \\
CFI & $\geq 0.95$ iyi uyum, 0.94-0.90 Kabul Edilebilir Uyum & 0.99 \\
NFI & $\geq 0.95$ iyi uyum, 0.94-0.90 Kabul Edilebilir Uyum & 0.99 \\
RMR & $\leq 0.05$ iyi uyum, 0.08-0.10 Kabul Edilebilir Uyum & 0.02 \\
\hline
\end{tabular}

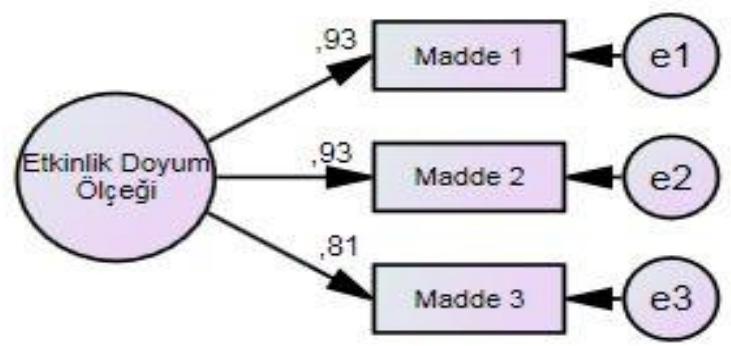

Şekil 1. Etkinlik Doyum Ölçeğinin Faktör Yapısı

\section{Ölçüt Bağıntılı Geçerlilik}

Etkinlik Doyum Ölçeği (EDÖ) ile Oxford Mutluluk Ölçeği Kısa Formu (OMÖ-K), Öznel Mutluluk Ölçeği (ÖMÖ), Yaşam Doyum Ölçeği (YDÖ), Rekreasyonel Akış Deneyim Ölçeği (RADÖ) arasındaki ilişkiler ölçüt bağıntılı geçerlilik kapsamında incelenmiştir. Analiz sonucu, EDÖ ile diğer ölçüm araçları arasında istatistiksel olarak anlamlı düzeyde düşük ilişki belirlenmiştir (Tablo 5). Bu durum EDÖ’nün uyum geçerliliğine sahip olduğuna kanıt oluşturmaktadır.

Tablo 5. Ölçüt Bağıntılh Geçerliliğe Yönelike Ilişki Düzeyleri

\begin{tabular}{lc}
\hline \multicolumn{1}{c}{ Ölçekler } & Etkinlik Doyum Ölçeği \\
\hline Oxford Mutluluk Ölcceği Kısa Formu & $0.11^{*}$ \\
Öznel Mutluluk Ölçeği & $0.44^{*}$ \\
Yaşam Doyum Ölçeği & $0.32^{*}$ \\
Rekreasyonel Akıș Deneyim Ölçeği & $0.32^{*}$ \\
\hline "p $\leq 0.05$
\end{tabular}

\section{Tartışma, Sonuç ve Öneriler}

Bu araştırmada Etkinlik Doyum Ölçeğinin (EDÖ) hem Türkçe geçerlik ve güvenirliğinin test edilmesi hem de psikometrik özelliklerinin incelenmesi amaçlanmıştır. Belirlenen amaç doğrultusunda, EDÖ’nün yap1 geçerliği "Doğrulayıc1 Faktör Analizi (DFA)" ve "Ölçüt Bağıntılı Geçerlik" yöntemiyle incelenmiş; güvenirlik düzeyi ise iç tutarlılık katsayısı analiziyle test edilmiştir. Elde edilen bulgular, Türkçe dilindeki EDÖ’nün orijinaliyle yakın psikometrik özellikler sahip olduğunu göstermektedir.

Ölçeğin faktör yapısını doğrulanıp doğrulanamayacağını tespit etmek amacıyla yapılan DFA sonucu, orijinal formda olduğu gibi EDÖ’nün 3 maddelik tek faktörlü yapısının korunduğunu ortaya koymuştur. Faktör yapısının değerlendirilmesinde sirasiyla " $\chi 2 / \mathrm{sd}=1.68$ ", "RMSEA $=0.04 "$, "SRMR $=0.00 "$, "NFI $=$ $0.99 "$, "CFI= 0.99"; "RMR = 0.02" uyum değerlerinin kullanıldığ1 ve analiz sonucu elde edilen bu model uyum değerlinin kabul edilebilir sınırlar içerisinde (Hooper, Coughlan ve Mullen, 2008, s. 53; Meydan ve Şeşen, 2015, s. 37; Tabachnick ve Fidell, 2006, s. 53) yer aldığı görülmektedir. Literatür incelendiğinde, 0.05 veya daha düşük bir "RMSEA" ve "SRMR" değeri mükemmel bir uyumu yansitırken, 0.10'un altındaki değerler kabul edilebilir bir uyum olarak gösterilir; 0.10 ’un üstündeki değerler ise kötü bir uyumu ifade etmektedir. Diğer uyum ölçütleri ise 0 ile 1 arasındaysa ve 1'e yakın ise modelin daha iyi uyum gösterdiği şeklinde yorumlanabilir (Byrne, 1998, s. 87; Jöreskog ve Sörbom, 2002, s. 156; Yılmaz ve İlhan Dalbudak, 2018, s. 528); ancak, literatür incelendiğinde, $\chi 2 /$ sd değeri üzerinde farkl görüşlerin olduğu, özelliklede araştırmacıların bu konuda birbirinden farklı değerlendirmeler yaptığı söylenebilir. Örneğin 
$\chi 2 /$ sd değerinin örneklem sayısına oldukça duyarlı olduğunu ifade eden $\mathrm{Hu}$ ve Bentler (1999, s. 27), örneklem sayısındaki artışın $\chi 2 /$ sd değerinin yükselmesine ve araştırma modellerinin ret edilmesine neden olabileceğini belirtmiştir. Ancak, Hooper vd. (2008, s.54) literatürde hangi değer aralıklarının bu istatistiksel sonuç için kabul edilebilir olduğu konusunda ortak bir fikir birliğinin oluşmadığını, dolayısıyla $\chi 2 / \mathrm{sd}$ değerini 2.0'a kadar kabul eden araştırmacıların (Tabachnick ve Fidell, 2006, s. 53) yanı sıra, 5.0'a kadar kabul edenlerin de olduğunu (Wheaton, Muthen, Alwin ve Summers, 1977, s. 99) ifade etmiştir.

EDÖ ile geçerliği kanıtlanmış olan çeşitli mutluluk ve doyum düzeylerini değerlendiren diğer ölçme araçları arasında ilişkiler ölçüt bağıntılı geçerliliğe kanıt sağlaması için incelenmiş, "Oxford mutluluk ölçeği kısa form", "öznel mutluluk", "yaşam doyum” ve" rekreasyonel akış deneyim” arasında istatiksel olarak anlamlı ve düşük düzeyde ilişkiler olduğu tespite dilmiştir. Literatür bu ilişki düzeylerinin destekler nitelikte çalışmaların yapıldığı görülmektedir (ör. Doğan ve Totan, 2013, s. 27). Ayrıca, çalısmada İç tutarlık testiyle güvenirliği belirlenen EDÖ’nün yüksek düzeyde güvenirliğe $(\alpha=0.91)$ sahip olduğu gözlemlenmiştir. Cronbach Alfa katsayısının 0.70 ve üzerinde olması güvenirlik için yeterli olacağı şeklinde yorumlanmaktadır (Büyüköztürk, 2008, s. 121). Funk vd. (2011, s. 260) tarafindan uyarlama çalışmasında EDÖ'nün güvenirlik katsayısını 0.78 olarak hesaplamıştır. Dolayısıyla araştırmada elde edilen güvenirlik katsayısı değerlerinin uyarlanan orijinal çalışma bulgusuyla paralellik gösterdiği de söylenebilir. Son olarak, EDÖ toplam puanının cinsiyet değişkeni açısından incelendiğinde kadın ya da erkek olmanın serbest zaman etkinliklerinden elde edilen doyum düzeyinde belirleyici bir ölçüt olmadığı sonucuna ulaşılmıştır.

Literatürde etkinlik katılımı sonucu oluşan doyum düzeyini ölçmek için farklı ölçüm aracıları mevcuttur ancak araştırmada kullanılan ölçek formun tek boyut ile ele alınması araştırmanın bu boyut çerçevesinde sınırlandırılarak incelendiğini göstermektedir. Katılımcıların amaçlı örneklem yöntemlerinden ölçüt örneklemin kullanılarak düzenli bir biçimde kitlesel rekreasyonel etkinliğe katıliyor olma ölçütüne göre belirlenmesi çalışmanın örneklem konusundaki sınıllllı̆ı̆nı göstermektedir. Bu sebeple, araştırmada elde edilen bulgular farklı bireysel etkinlik türlerine katılan kişilerden elde edilecek bulgularla doğrudan genelleştirilemez. Gelecekte diğer farklı kitlesel faaliyetlere katılan insanların oluşturacağı örneklem gruplarıla benzer çalışmaların yapılması ilgili literatürde önemli bir boşluğu dolduracaktır; ayrıca, bireysel etkinliklere katılan kişilerin oluşturacağı örneklem üzerinde de bu ölçeğin yap1 geçerliği ve güvenirliğinin test edilmesi araştırmacılara önerilebilir. İleride yapılacak bu tür araştırma bulgularının çeşitli rekreasyonel etkinliklerden elde edilen doyumun da net bir şekilde anlaşılma konusunda da fikir sunacağı söylenebilir.

\section{Etik Beyan}

"Rekreasyonel Faaliyetlerde Etkinlik Doyum Ölçeğinin Türkşe Uyarlaması" başlıklı çalışmanın yazım sürecinde bilimsel kurallara, etik ve alınt kurallarına uyulmuş; toplanan veriler üzerinde herhangi bir tahrifat yapilmamış ve bu çalışma herhangi başka bir akademik yayın ortamına değerlendirme için gönderilmemiştir. Gerekli olan etik kurul izinleri Bartın Üniversitesi Sosyal ve Beşeri Bilimleri Etik Kurulu'nun 12.03.2021 tarih ve 3 sayll toplantısında alınmıstır.

\section{Kaynakça}

Addis, M. ve Holbrook, M. B. (2001). On the conceptual link between mass customization and experiential consumption: An explosion of subjectivity. Journal of Consumer Behavior, 1, $50-66$.

Ateca-Amestoy, V. (2011). Leisure and subjective well-being. In S. Cameron (Ed.), Handbook on the economics of leisure (pp. 52-76). Cheltenham, England: Edward Elgar Publishing.

Ayhan, C. ve Eskiler, E. (2020). Rekreasyonel katılımcılarda akış deneyiminin ölçülmesi: Ölçek geliştirme ve doğrulama. Journal of Human Sciences, 17(4), 1297-1311.

Beard, J. G. ve Ragheb, M. G. (1980). Measuring leisure satisfaction. Journal of Leisure Research, 12, 20-33.

Byrne, M. B. (1998). Structural equation modeling with LISREL, PRELIS and SIMPLIS: Basic concepts, applications, and programming. Lawrence Erlbaum Associates, Mahwah-New Jersey, London.

Csikszentmihalyi, M. (1990). Flow: The psychology of optimal experience. New York: HarperCollins.

Csikszentmihalyi, M., Larson, R. ve Prescott, S. (1977). The ecology of adolescent activity and experience. Journal of Youth and Adolescence, 6, 281-294.

Diener, E., Emmons, R. A., Larsen, R. J. ve Griffin, S. (1985). The satisfaction with life scale. Journal of Personality Assessment, 49(1), 71-75.

Doğan, T. ve Akıncı Çötok, N. (2011). Oxford mutluluk ölçeği kısa formunun Türkçe uyarlaması geçerlik ve güvenirlik çalışması. Türk Psikolojik Danışma ve Rebberlik Dergisi, 4(36), 165-172.

Doğan, T. ve Totan, T. (2013). Psychometric properties of Turkish version of the subjective happiness scale. The Journal of Happiness and Well-Being, 1(1), 23-31. 
Filo, K., Funk, D. C. ve O’Brien, D. (2009). The meaning behind attachment: Exploring camaraderie, cause, and competency at a charity sport event. Journal of Sport Management, 23, 361-387.

Funk, D. C., Jordan, J., Ridinger, L. ve Kaplanidou, K. (2011). Capacity of mass participant sport events for the development of activity commitment and future exercise intention. Leisure Sciences, 33, 250-268.

Hills, P. ve Argyle, M. (2002). The Oxford Happiness Questionnaire: A compact scale for the measurement of psychological well-being. Personality and Individual Differences 33, 1073-1082.

Hooper, D., Coughlan, J. ve Mullen, M. R. (2008). Structural equation modeling: Guidelines for determining model fit. The Electronic Journal of Business Research Methods, 6(1), 53-60.

Hu, L. ve Bentler, P. M. (1999). Cutoff criteria for fit indexes in covariance structure analysis: Conventional criteria versus new alternatives. Structural Equation Modeling: A Multidisciplinary Journal, 6(1), 1-55.

Jöreskog, K. G. ve Sörbom, D. (2002). The Student Editions of LISREL 8.53 for Windows. Lincolnwood. IL: Scientific Software International, Inc.

Karlı, Ü., Polat, E., Yılmaz, B. ve Koçak, S. (2008). Serbest zaman tatmin ölçeği’nin (sztö-uzun versiyon) geçerlilik ve güvenilirlik çalışması. Spor Bilimleri Dergisi, 19(2), 80-91.

Lyubomirsky, S. ve Lepper, H. S. (1999). A measure of subjective happiness: Preliminary reliability and construct validation. Social Indicators Research, 46, 137-155.

Meydan, C. ve Şeşen, H. (2015). Yapısal eşitlik modellemesi Amos uygulaması. Ankara: Detay Yayıncılık.

Newman, D. B., Tay, L. ve Diener, E. (2014). Leisure and subjective well-being: A model of psychological mechanisms as mediating factors. Journal of Happiness Studies, 15(3), 555-578.

Oliver, R. L. (1980). A cognitive model of the antecedents and consequences of satisfaction decisions. Journal of Marketing Research, 17, 460-469.

Oliver, R. L. (1997). Satisfaction: A behavioral perspective on the consumer (2nd ed.). New York, NY: McGraw-Hill.

Stiglitz, J. E., Sen, A. ve Fitoussi, J. P. (2009). Report by the commission on the measurement of economic performance and social progress. [Available online at: https://www.economie.gouv.fr/files/finances/presse/dossiers_de_presse/090914mesure_perf_eco_progres_s ocial/synthese_ang.pdf] Erişim Tarihi: 10 Şubat 2021.

Tabachnick, B. G. ve Fidell, L. S. (2006). Using multivariate statistics (Fifth edition). New York: Pearson Education.

Theodorakis, N. D., Kiki Kaplanidou, K. ve Karabaxoglou, I. (2015). Effect of event service quality and satisfaction on happiness among runners of a recurring sport event. Leisure Sciences, 37, 87-107.

Van Praag, B. M. ve Ferrer-i-Carbonell, A. (2004). Happiness quantified: A satisfaction calculus approach. Oxford, England: Oxford University Press.

Wheaton, B., Muthen, B., Alwin, D. F. ve Summers, F. (1977). Assessing reliability and stability in panel models. JSTOR, [Available online at: https://www.jstor.org/stable/pdf/270754.pdf] Erişim Tarihi: 10 Ocak 2021.

Yetim, Ü. (1991). Kişisel projelerin organizasyonu ve örüntüsü açısından yaşam doyumu (Doktora Tezi). Ege Üniversitesi Sosyal Bilimler Enstitüsü, İzmir.

Yilmaz, V. ve Ilhan Dalbudak, Z. (2018). Investigation of intermediary variable effect: An application on high speed train operations. International Journal of Management, Economics and Business, 14(2), 517-534.

\section{EXTENDED ABSTRACT}

Knowing the level of satisfaction as a result of participating in leisure activities greatly contributes to researchers in analyzing such activities from a social psychological perspective. Some researchers have an opinion that the satisfaction arising from such activities will contribute to the discovery of relationships in many issues such as people's attitudes towards activities, general well-being and life satisfaction levels (Ateca-Amestoy, 2011; Newman, Tay, \& Diener, 2014; Stiglitz, Sen, \& Fitoussi, 2009; Van Praag \& Ferreri-Carbonell, 2004). For this reason, the time spent in leisure activities and to what extent people are satisfied with the activities carried out are mainly tried to be evaluated with cross-sectional research designs and less with longitudinal research designs. Regardless of the research designs used, it can be thought that satisfaction from leisure activities varies among people, making this an interesting phenomenon. Although different concepts and measurement tools are used to understand the satisfaction created by the participation in recreational activities in individuals, it is seen that these measurement tools mainly measure the characteristics of the individuals related to the subject at different levels. In the study, the validity and reliability of the tested Event Satisfaction Scale basically group or mass participation when you take their operations centers, while in Turkey was determined to be no work in various databases for nature satisfaction scale of these activities. Therefore, this situation prompts researchers to add a valid and reliable measurement tool to the Turkish language in the literature. The study group of the study consisted of 39 people who receive recreational physical activity services from various health and wellness clubs in Ankara. In the process of determining the participant group, criterion sampling method, that is one of the purposeful sampling methods, was used. The scales used in the study are as follows, respectively. Event Satisfaction Scale (ESS) was developed by Oliver (1980) and adapted by Funk et al. (2011). Oxford Happiness Scale Short Form (OHQ-SF) was developed by Hills and Argyle (2002) and made Turkish 
adaptation by Doğan and Akıncı Çötok (2010). Subjective Happiness Scale (SHS) was developed by Lyubomirsky and Lepper (1999), and the Turkish adaptation was carried out by Doğan and Totan (2013). Life Satisfaction Scale (LSS) developed by Diener et al. (1985), and made Turkish adaptation by Yetim (1991). The Recreational Flow Experience Scale (RFES) has been validated by Ayhan and Eskiler (2020) to determine the psychological satisfaction levels of people as a result of participating in recreational activities. The data collected from the participants in the presence of the researcher were evaluated in SPSS-23 and AMOS-18 statistical package programs. Whether the obtained data meets the prerequisite for the parametric test was examined with the univariate normality distribution test result and because of its normal distribution, the parametric estimation method "Maximum Likelihood: ML" was preferred in the study. First, "Confirmatory Factor Analysis (CFA)" was applied in order to test model fit of the scale, which was translated into Turkish, and to verify the factor structure. In addition, Cronbach's Alpha coefficients were determined at the sub-dimension level of the measurement tool for the internal reliability of the Turkish form; In addition, "Composite Reliability (CR)" for the structure reliability of the measurement tools and "Average Variance Extracted (AVE)" for the convergent validity and discriminant validity were calculated in the study (Table 1). The CFA result, which was made to determine whether the factor structure of the scale could be confirmed or not, revealed that the 3-item single-factor structure of the ESS was preserved as in the original form, and also, the findings obtained show that the Turkish language ESS has psychometric properties close to the original. Relationships between ESS and other measurement tools that assess the validity of various levels of happiness and satisfaction were examined to provide evidence for criterion-related validity. It has been determined that there are significant and low level relationships. In the literature, there are different measurement tools to measure the level of satisfaction resulting from activity participation, but considering the scale form used in the study with a single dimension demonstrates that the study is limited within the framework of this dimension. Conducting similar studies with sample groups of people who participate in other different mass events in the future will fill an important gap in the relevant literature; In addition, it might be suggested to researchers to test the construct validity and reliability of this scale on the sample formed by the people participating in individual activities. It can be said that the findings of such research to be carried out in the future will also provide an idea for a clear understanding of the satisfaction obtained from various recreational activities. 